\title{
Considering the Order and Symmetry to Improve the Traditional RVA for Evaluation of Hydrologic Alteration of River Systems
}

\author{
Kairong Lin ${ }^{1} \cdot$ Youqin $\operatorname{Lin}^{1} \cdot$ Pan Liu ${ }^{2,3}$. \\ Yanhu $\mathrm{He}^{1} \cdot$ Xinjun $\mathrm{Tu}^{1}$
}

Received: 29 December 2015 / Accepted: 19 September 2016 /

Published online: 28 September 2016

(C) The Author(s) 2016. This article is published with open access at Springerlink.com

\begin{abstract}
Hydrologic alteration is one of the key factors influencing the aquatic health of a river basin, particularly that of highly fragmented rivers. In this study, we propose an improved range of variability approach (RVA) by considering the order and symmetry of indicators of hydrologic alteration (IHA) to comprehensively assess the hydrologic alteration of river flows. Three indices, i.e., index for the alteration of periodicity, index for the alteration of trend, and index for the alteration of symmetry, were used to improve the traditional RVA for evaluation of hydrologic alteration of river systems. Two main control stations located in the upper Pearl River Delta, the Sanshui and Makou stations, were selected as case studies. The results show that (1) each evaluation index reflects only partial characteristics of the alteration of each IHA parameter, which vary over the stations, and (2) the traditional RVA underestimates hydrologic alteration, because the trend and periodicity components and symmetry in the temporal order of IHAs were significantly altered, while the results of the traditional RVA varied slightly for some IHAs, e.g., the multiday maximum flow at the Sanshui station and monthly flows for May, July, and September at the Makou station. These indicated that, by considering frequency, trend, periodicity, and symmetry, the improved RVA provides a more accurate quantitative evaluation of ecological flow alteration.
\end{abstract}

Keywords Hydrologic alteration · Range of variability approach · Periodicity · Trend - Symmetry

Pan Liu

liupan@whu.edu.cn

1 Department of Water Resources and Environment, Sun Yat-sen University, Guangzhou 510275, China

2 State Key Laboratory of Water Resources and Hydropower Engineering Science, Wuhan University, Wuhan 430072, People's Republic of China

3 Hubei Provincial Collaborative Innovation Center for Water Resources Security, Wuhan 430072, China 


\section{Introduction}

Hydrologic alterations and their impact on ecosystems have been extensively studied using numerous statistical tools and methods (Chen et al. 2007; Ouyang et al. 2011; Sun and Feng 2013; Laize et al. 2014; Mittal et al. 2016). The indicators of hydrologic alteration (IHA) developed by Richter et al. (1996) and supported by The Nature Conservancy (TNC) in the United States (Richter et al. 1996) is one of the most widely used tools (Lin et al. 2014a) to evaluate hydrologic alteration of river systems. Based on IHA method, the range of variability approach (RVA) was developed to quantitatively evaluate the alteration degree for a single hydrologic parameter of IHA (Richter et al. 1996).

Although the RVA is being extensively employed for assessing the alteration of flow regimes, it still has potential limitations (Richter et al. 2006; Shiau and Wu 2008). For example, the traditional RVA only considers variations in parameter values within the target range, and the value and frequency of hydrologic parameters outside the target range are not considered (Shiau and Wu 2008). As a result, several modifications have been proposed to improve the performance of the traditional RVA. Shiau and Wu (2008) proposed a Histogram Matching Approach (HMA) to assess alterations in flow regimes on the basis of the degree of histogram dissimilarity by employing the quadratic-form distance between frequency vectors of pre- and post-impact histograms using IHA and described the complete variance of hydrologic alterations (Yang et al. 2012). Kim and Singh (2014) established an entropybased multi-criteria decision method for assessing hydrologic alterations in biologically relevant flow regimes. However, all these methods do not consider the temporal order of each IHA, which is also significantly important for an ecosystem (Yang et al., 2014). Therefore, Yang et al. (2014) proposed a revised RVA that considers both frequency and periodicity calculated using maximum entropy spectral analysis.

Any time series can be decomposed into three components (Brockwell and Davis 2002): periodic, trend, and random noise components. However, the study by Yang et al. (2014) did not consider the trend and symmetry of each IHA. Moreover, one major limitation of this revised RVA is due to the uncertainty in periodic time identification processes. Accordingly, Yang et al. (2014) suggested that relatively better periodic time identification methods must be developed in the future to improve the applicability of this method. Therefore, more indices are required to more synthetically evaluate the alteration of each IHA parameter.

In addition, river deltas, the primary link between the land and ocean, deliver terrigenous materials such as fresh water, sediments, and nutrients into the sea (Liu et al. 2014). In the past few decades, river delta systems have become increasingly complicated owing to climate change and human activities, which not only significantly affect the geomorphology of river channels but also alter hydrologic processes and ecological environment (e.g., Bott et al. 2006). The Pearl River flows into the South China Sea (SCS), and the Pearl River Delta (PRD) is the low-lying area surrounding the Pearl River estuary. Since the Pearl River is one of the most densely urbanized regions in the world, it is significantly contribute to the socioeconomic development of China (Ericson et al. 2006). The PRD consists of two alluvial deltas, i.e., the Northwest and Dongjiang river deltas, separated by the core branch of the Pearl River. Some studies have investigated the impact of climate change and human activities on water resources in the PRD (e.g., Dai et al. 2008; Chen et al. 2012; He et al. 2015). As the fastest developing region in China, the hydrology and morphology of the PRD have been predominantly dictated by human activities over the last 20 years, which have caused many environmental problems such as floods, saltwater intrusion, and storm surges. However, variations in the PRD's 
environmental flow, including magnitude, frequency, duration, timing of flow regime, and rate of change, which are well recognized by ecologists as primary drivers for numerous fundamental ecological processes in riverine ecosystems, have not been thoroughly investigated (Poff and Zimmerman 2010). Furthermore, updated flow regime data will be helpful for assessing hydrologic alteration and its possible causes in this area.

Therefore, the objectives of the present study are as follows: (1) To improve the traditional RVA for evaluation of hydrologic alteration of river systems. (2) To apply the propose improvement in the PRD.

This paper is organized as follows. First, the IHA and RVA methodologies are briefly described. Thereafter, the three indices, including their definitions and meanings, are presented. The three indices are then employed to assess the hydrologic alteration within the PRD. Subsequently, causes of hydrologic alteration in the PRD are discussed. Finally, the primary findings are discussed, and conclusions are drawn.

\section{Methodology}

\subsection{Indicators of Hydrologic Alteration}

In this study, the IHA statistical package developed by Richter et al. (1996) and supported by TNC was used to evaluate the hydrologic alteration. The IHA computes 33 parameters, including five characteristics of a flow regime referred to as the magnitude of monthly water conditions, magnitude and duration of annual extreme conditions, timing of annual extreme conditions, frequency and duration of high and low pulses, and rate and frequency of water condition changes. In this study, the Pearl River basin is a large basin, and no zero-flow day was ever observed at the study gaging stations during the study period, and hence, the "number of zero flow days" was not considered and only 32 parameters were used in this study.

\subsection{Range of Variability Approach}

Based on the IHA method, the RVA was used to quantify the degree of alteration for each hydrologic parameter in IHA, which is called the traditional RVA in this this study.

The degree of hydrologic alteration of IHAs $\left(D_{R}\right)$ is defined as follows:

$$
D_{R}=\left|\frac{N_{o}-N_{e}}{N_{e}}\right|
$$

where $N_{o}$ and $N_{e}$ are the observed and expected number of years, respectively, whose values fall within the target range (between the 25th and 75th percentile values) (Hu et al. 2008, Gao et al. 2012) in the post-impact period of IHAs.

Although the traditional RVA aims to detect the alteration of a hydrologic flow regime, it is unable to reflect whether the frequency of a hydrologic parameter within the target range increases or decreases. To solve this problem, a signed value was employed as follows:

$$
D_{R}=\frac{N_{o}-N_{e}}{N_{e}}
$$


Note that a positive $D_{R}$ value indicates that the frequency of the parameter within the target range has increased from the pre- to the post-impact period, whereas a negative $D_{R}$ value indicates that the frequency of the parameter has decreased.

\subsection{Indices for Assessing Hydrologic Alteration}

\subsubsection{Index for the Alteration of Periodicity}

The wavelet analysis method can simultaneously reveal the local characteristics of the time series in both the time and frequency domains In this study, the Morlet wavelet is selected as the mother wavelet function consisting of a plane wave modulated by a Gaussian as follows:

$$
\Psi(t)=\pi^{-1 / 4} e^{i \omega_{0} t} e^{-t^{2} / 2}
$$

where $t$ is the time parameter, $i \in Z$, and $\omega_{0}$ is the nondimensional frequency with a typical value of $\omega_{0}=6$ (Farge 1992).

The discrete wavelet transform of a sequence $x_{n}$ is

$$
W_{f}(a, b)=|a|^{-\frac{1}{2}} \sum_{i=1}^{N} x_{i} \Psi^{*}\left(\frac{i \delta t-b}{a}\right)
$$

where $W_{f}(a, b)$ is the wavelet transform coefficient and $\Psi^{*}$ is the complex conjugate. Furthermore, $\delta t$ is the time space, and $a$ and $b$ are the scale and translation parameters, respectively.

According to Torrence and Compo (1998), the relation between scale $a$ and periodic time $T$ is

$$
T=\frac{4 \pi a}{\omega_{0+} \sqrt{2+\omega_{0}^{2}}}=1.033 a
$$

For each IHA, the index for the alteration of periodicity is defined as follows (Yang et al., 2014):

$$
I P_{i}=\min \left(\frac{1}{N} \sum_{j, k=1}^{N_{i}} \frac{\left|T_{\text {pre }, j}-T_{\text {post }, k}\right|}{\max \left(T_{\text {pre }, j}, T_{\text {post }, k}\right)}\right)
$$

where $N_{i}$ is the maximum number of periodic time of the $i$ th IHA in pre- and post-impact periods, and additional zeros periodic time will be available if the numbers of periodic times are unequal. It should be noted that each periodic time can be used only once. Further, $T_{p r e, j}$ and $T_{\text {post }, j}$ are the $j$ th and $k$ th periodic times of the $i$ th IHA of the pre- and post-impact periods, respectively.

\subsubsection{Index for the Alteration of Trend}

In this study, Mann-Kendall trend analysis was used to analyze the trends of IHAs. The Mann-Kendall trend analysis method defines a variable S as follows:

$$
S=\sum_{k=1}^{n-1} \sum_{j=k+1}^{n} \operatorname{sgn}\left(x_{i}-x_{j}\right)
$$


The statistically significant trend was then evaluated using the $\mathrm{Z}$ value as follows:

$$
Z=\left\{\begin{array}{l}
\frac{S-1}{\sqrt{\operatorname{Var}(S)}}, S>0 \\
0, S=0 \\
\frac{S+1}{\sqrt{\operatorname{Var}(S)}}, S<0
\end{array}\right.
$$

Further, the standard normal cumulative distribution function $\left(F_{n}\right)$ under significance level $\alpha$ is given by $F_{n}\left(Z_{1-\alpha / 2}\right)=1-\alpha / 2$. If $|Z|>Z_{1-\alpha / 2}$, and the hypothesis of a two-sided test can be accepted. A positive value $Z$ indicates an upward trend, whereas a negative value indicates a downward trend (Gerstengarbe and Werner 1999; Karabork 2007). In this study, $\alpha$ is set to be 0.05 , and $\left|Z_{1-\alpha / 2}\right|$ equals 1.96 . Namely, for a time series, if $Z>1.96$ or $Z<-1.96$, it exhibits a significant increasing or decreasing trend at the 0.05 level.

In this study, the index for the alteration of trend (IT) is defined as follows:

$$
I T=\left\{\begin{array}{c}
\frac{\left|Z_{\text {pre }}-Z_{\text {post }}\right|}{\max \left(\left|Z_{\text {pre }}\right|,\left|Z_{\text {post }}\right|\right)}, Z_{\text {pre }} \cdot Z_{\text {post }}>0 \\
-\frac{\left|Z_{\text {pre }}-Z_{\text {post }}\right|}{\max \left(\left|Z_{\text {pre }}\right|,\left|Z_{\text {post }}\right|\right)}, Z_{\text {pre }} \cdot Z_{\text {post }}<0
\end{array}\right.
$$

where $Z_{\text {pre }}$ and $Z_{\text {post }}$ indicate the $Z$ values of the pre- and post-impact periods, respectively. It should be noted that a positive IT value indicates that the trend is consistent in the pre- and post-impact periods, whereas a negative IT value indicates that the trend has been reversed from the pre- to the post-impact period.

\subsubsection{Index for the Alteration of Symmetry}

In the traditional RVA method, only the frequencies of hydrologic parameters within the target range are considered, while those outside the target range are totally ignored. In order to overcome the drawback of the traditional RVA, in which the distribution of the frequency of the time series is ignored, the index for the alteration of symmetry (IS) is proposed as follows:

$$
\text { IS }=\left\{\begin{array}{c}
0, N_{u p}=N_{\text {low }}=0 \\
\frac{N_{u p}-N_{\text {low }}}{N_{u p}+N_{\text {low }}}, \text { others }
\end{array}\right.
$$

where $N_{u p}$ and $N_{\text {low }}$ are the number of years above the upper target and below the lower target, respectively. It should be noted that a positive IS value represents an upward bias series, namely, the hydrologic parameter has increased after impact. Contrarily, a negative IS value indicates a downward bias with the hydrologic parameter decreasing in the post-impact period.

The flow chart of the improved RVA is shown in Fig. 1.

\section{Study Area and Data}

The PRD is the low-lying area surrounding the Pearl River estuary and is formed by the converging West River and North River at the Sixianjiao channel (Fig. 2). The West River and North River provide the essential water supply to several major cities, including Foshan and 


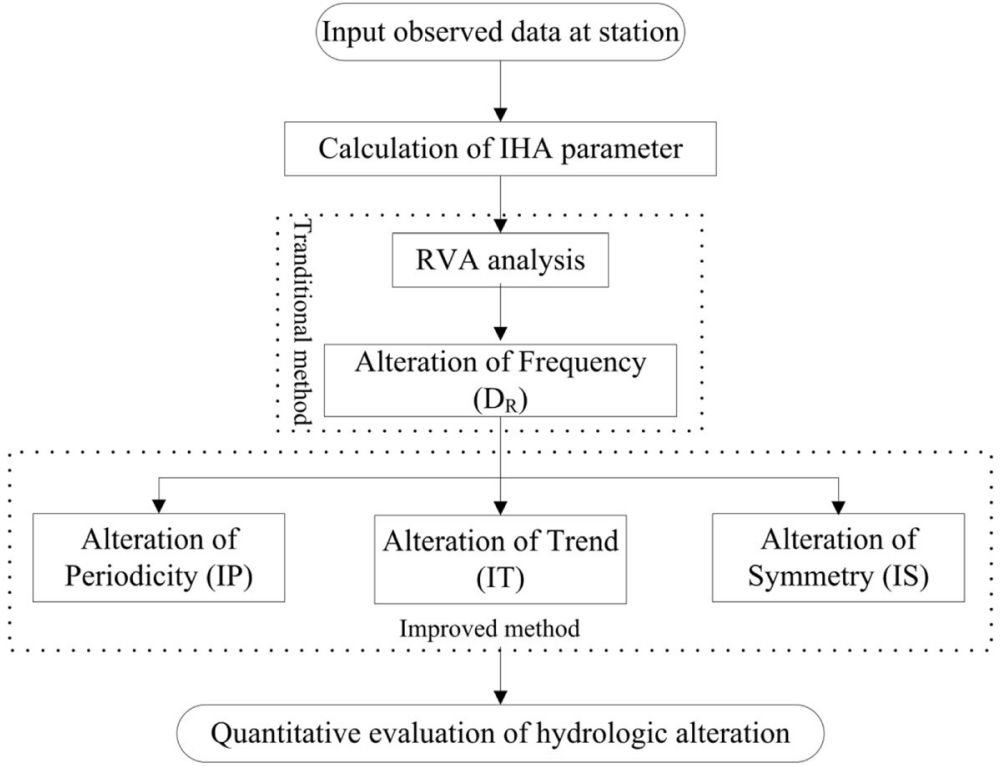

Fig. 1 Flow chart of the traditional and improved RVA

Guangzhou in the PRD region. Some studies have investigated the impact of climate change and human activities on the water resources in the PRD (e.g., Luo et al. 2007; Liu et al. 2014). Over the last 20 years, the hydrology and morphology of the PRD, the fastest developing

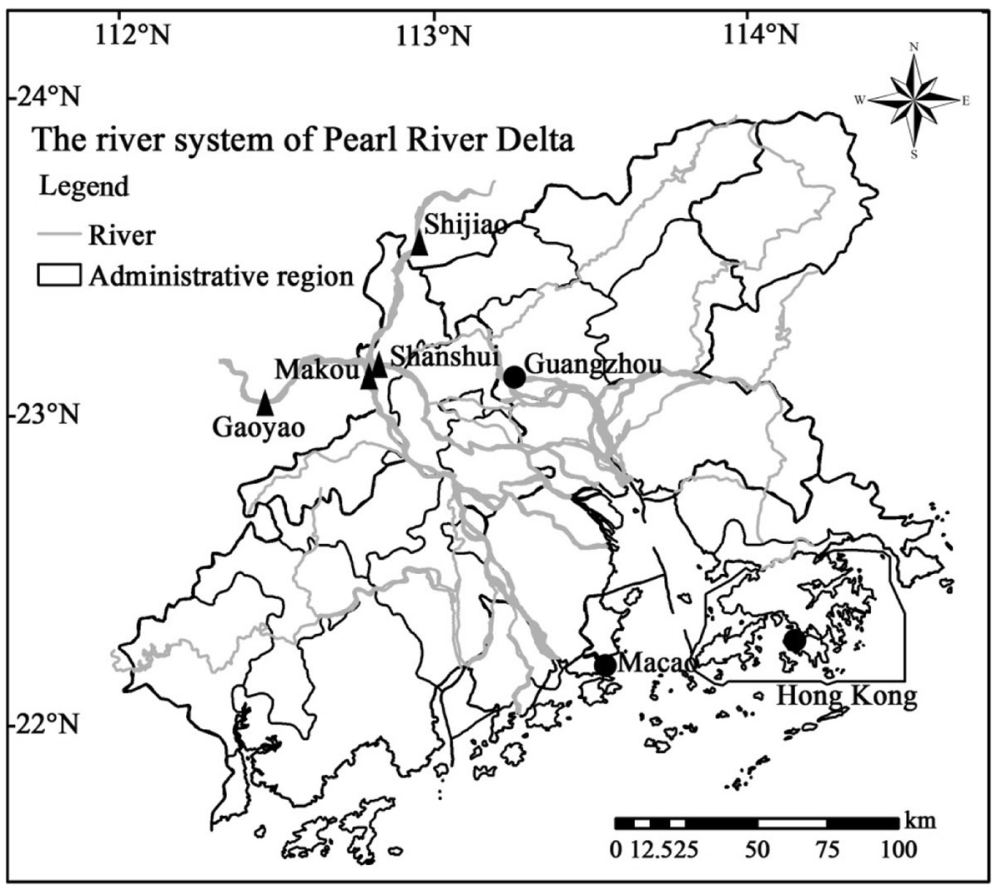

Fig. 2 Map of the river system of the Pearl River Delta 
region in China, have been predominantly dictated by human activities, which have caused environmental and ecological problems, such as floods, saltwater intrusion, and storm surges.

In this study, the daily streamflow data was used to investigate the variations in flow regime at the two main control hydrologic stations, i.e., the Maokou station on the West River and the Sanshui station on the North River (Fig. 2). As shown in Fig. 2, two other hydrologic stations the Gaoyao and Shijiao stations are the control stations for these two main rivers that drain into the PRD, and Makou and Sanshui stations control the flow across the PRD into the SCS. The hydrologic data ranges from 1/1/1960 to $12 / 31 / 2009$ at the Makou and Sanshui stations. The hydrologic data were obtained from the Bulletins of Chinese River Sediment compiled by the Ministry of Water Resources of China (MWRC) and provided by the Water Bureau of Guangdong Province. Since the 1990s, large reservoirs, such as the Yantan (constructed in 1992 year), Bailongtan (constructed in 1996 year), and Tianshengqiao (constructed in 1997 year) reservoirs, have been constructed on the West River, and the total storage capacity of these reservoirs is up to $138.8 \times 10^{8} \mathrm{~m}^{3}$. As a result, streamflow has been changed due to the reservoir operation (Liu et al. 2006; Li et al. 2010; Liu et al. 2015). Additionally, another human activity uneven sand dredging began in the late 1980s. Therefore, the long-term flow records were divided into pre- and post-impact periods of 1960-1989 and 1990-2009, respectively, for IHA analyses in this study.

\section{Results}

\subsection{RVA Result}

For RVA analysis, the 25th and 75th percentiles from the pre-impact period were set as the boundaries of the RVA target for the 32 IHA parameters to define the extent of natural flow regime. The degree of hydrologic alteration $\left(D_{R}\right)$ values at Sanshui and Makou stations calculated using Eq. (2) are summarized in Table 1.

Alteration of hydrologic conditions can be clearly seen at the Sanshui station. As listed in Table 1, ten IHAs have a frequency alteration of $100 \%$, as assessed by the traditional RVA. Figure 3 shows the Monthly March Flow and Julian date of annual maximum, we can observe that both $\mathrm{D}_{\mathrm{R}}$ values are $100 \%$; however, the hydrologic alterations are completely opposite. No frequency is within the pre-determined RVA target range of the Monthly March Flow parameter (Fig. 3a), whereas they were totally within the target range of the Julian Date of Annual Maximum (Fig. 3b). These results show that the signed $D_{R}$ value is useful for distinguishing the specific variations in the frequency of interest.

As can be seen in Table 1, 29 out of 32 parameters have negative $D_{R}$ values at Sanshui station, indicating that the frequency of the majority of IHAs have decreased within the RVA target ranges. The RVA results at Makou station are more complicated with 18 and 11 parameters having negative and positive signs, respectively. At the Makou station, the frequencies of parameters in the magnitude of monthly river flow have decreased, except for the monthly flow for June and September. Moreover, the frequencies of multiday minimum flows, except for the 7-day minimum flow, have increased between the RVA target ranges from the pre- to post-impact period, while the 7-, 30-, and 90-day maximum flows have decreased at Makou station. 
Table 1 Hydrologic alteration at Sanshui and Makou stations

\begin{tabular}{|c|c|c|c|c|c|c|c|c|c|c|}
\hline \multirow[t]{2}{*}{ Parameter } & \multicolumn{5}{|c|}{ Sanshui Station } & \multicolumn{5}{|c|}{ Makou station } \\
\hline & IP & IT & IS & & $\mathrm{D}_{\mathrm{R}}$ & IP & IT & IS & & $\mathrm{D}_{\mathrm{R}}$ \\
\hline \multicolumn{11}{|c|}{ Group1: Magnitude of monthly river flow } \\
\hline January & 0.30 & 0.65 & 1.00 & $\uparrow$ & -0.90 & 0.67 & 0.68 & -0.18 & $\downarrow$ & -0.70 \\
\hline February & 0.41 & 0.84 & 1.00 & $\uparrow$ & -0.90 & 0.65 & 0.32 & -0.08 & $\downarrow$ & -0.30 \\
\hline March & 0.82 & -1.06 & 1.00 & $\uparrow$ & -1.00 & 0.33 & -1.02 & 0.33 & $\uparrow$ & -0.20 \\
\hline April & 0.75 & -1.36 & 0.75 & $\uparrow$ & -0.60 & 0.75 & 0.97 & -0.29 & $\downarrow$ & -0.40 \\
\hline May & 0.17 & -1.30 & 0.69 & $\uparrow$ & -0.30 & 0.19 & -1.36 & -0.64 & $\downarrow$ & -0.10 \\
\hline June & 0.35 & -1.25 & 1.00 & $\uparrow$ & 0.00 & 0.56 & 0.46 & 0.00 & - & 0.20 \\
\hline July & 0.74 & 0.60 & 1.00 & $\uparrow$ & -0.40 & 1.00 & 0.69 & 0.64 & $\uparrow$ & -0.10 \\
\hline August & 0.50 & 0.62 & 0.67 & $\uparrow$ & -0.20 & 0.24 & 0.48 & -0.50 & $\downarrow$ & -0.20 \\
\hline September & 0.55 & -1.74 & 0.50 & $\uparrow$ & -0.60 & 0.55 & -1.64 & -1.00 & $\downarrow$ & 0.10 \\
\hline October & 0.40 & -1.54 & 1.00 & $\uparrow$ & 0.00 & 0.33 & -1.06 & -0.54 & $\downarrow$ & -0.30 \\
\hline November & 0.69 & 0.92 & 1.00 & $\uparrow$ & -0.40 & 0.36 & 0.29 & -0.71 & $\downarrow$ & -0.40 \\
\hline December & 0.63 & 0.28 & 1.00 & $\uparrow$ & -1.00 & 0.26 & -1.39 & -0.17 & $\downarrow$ & -0.20 \\
\hline \multicolumn{11}{|c|}{ Group2: Magnitude of annual extreme water conditions } \\
\hline 1-day minimum & 0.40 & -1.07 & 1.00 & $\uparrow$ & -0.70 & 0.63 & 0.73 & -0.33 & $\downarrow$ & 0.10 \\
\hline 3-day minimum & 0.28 & 0.85 & 1.00 & $\uparrow$ & -1.00 & 0.29 & 0.63 & -0.33 & $\downarrow$ & 0.10 \\
\hline 7-day minimum & 0.27 & 0.81 & 1.00 & $\uparrow$ & -1.00 & 0.55 & 0.45 & -0.45 & $\downarrow$ & -0.10 \\
\hline 30-day minimum & 0.54 & 0.74 & 1.00 & $\uparrow$ & -1.00 & 0.56 & 0.41 & -0.20 & $\downarrow$ & 0.00 \\
\hline 90-day minimum & 0.30 & 0.81 & 1.00 & $\uparrow$ & -1.00 & 0.21 & 0.02 & -0.25 & $\downarrow$ & 0.20 \\
\hline 1-day maximum & 0.35 & -1.53 & 0.69 & $\uparrow$ & -0.30 & 0.54 & 0.68 & 0.33 & $\uparrow$ & 0.10 \\
\hline 3-day maximum & 0.35 & -1.63 & 0.67 & $\uparrow$ & -0.20 & 0.39 & 0.68 & 0.33 & $\uparrow$ & 0.10 \\
\hline 7-day maximum & 0.34 & -1.85 & 0.82 & $\uparrow$ & -0.10 & 0.36 & -1.16 & 0.09 & $\uparrow$ & -0.10 \\
\hline 30-day maximum & 0.24 & -1.37 & 0.69 & $\uparrow$ & -0.30 & 0.24 & -1.19 & -0.08 & $\downarrow$ & -0.30 \\
\hline 90-day maximum & 0.73 & -1.24 & 1.00 & $\uparrow$ & -0.30 & 1.00 & 0.67 & -0.08 & $\downarrow$ & -0.30 \\
\hline base flow index & 0.38 & 0.83 & 1.00 & $\uparrow$ & -1.00 & 0.49 & 0.62 & 0.08 & $\uparrow$ & -0.30 \\
\hline \multicolumn{11}{|c|}{ Group3: Timing of annual extreme water conditions } \\
\hline Julian date of annual minimum & 0.63 & 0.73 & 0.00 & - & -0.60 & 0.27 & 0.43 & 0.00 & - & 0.40 \\
\hline Julian date of annual maximum & 0.31 & 0.18 & 0.00 & - & 1.00 & 0.67 & 0.39 & 0.00 & - & 1.00 \\
\hline \multicolumn{11}{|c|}{ Group4: Frequency and duration of high and low pulses } \\
\hline Number of low pulses & 0.18 & -1.36 & -0.63 & $\downarrow$ & -0.60 & 0.86 & 0.92 & 0.71 & $\uparrow$ & 0.30 \\
\hline Duration of low pulses & 0.29 & 0.93 & -1.00 & $\downarrow$ & -1.00 & 0.76 & 0.86 & 0.14 & $\uparrow$ & 0.30 \\
\hline Number of high pulses & 0.18 & -1.77 & -0.75 & $\downarrow$ & -0.60 & 0.67 & -1.45 & 0.00 & - & 0.00 \\
\hline Duration of high pulses & 0.41 & 0.70 & 0.60 & $\uparrow$ & -0.50 & 0.41 & 0.91 & -0.27 & $\downarrow$ & -0.10 \\
\hline \multicolumn{11}{|c|}{ Group5: Rate and frequency of water-condition changes } \\
\hline Rise rate & 0.67 & -1.07 & 1.00 & $\uparrow$ & -0.60 & 0.18 & -1.61 & 0.33 & $\uparrow$ & 0.10 \\
\hline Fall rate & 1.00 & 0.86 & -1.00 & $\downarrow$ & -0.70 & 0.69 & -1.10 & -0.60 & $\downarrow$ & -0.50 \\
\hline Number of reversals & 0.79 & 0.80 & 1.00 & $\uparrow$ & -1.00 & 0.70 & 0.36 & 0.88 & $\uparrow$ & -0.60 \\
\hline
\end{tabular}

' $\uparrow$ ' means upward bias,

' $\downarrow$ ' means downward bias and

'-' means no bias 


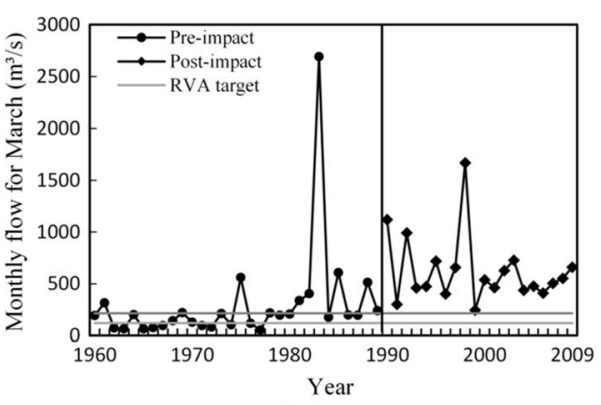

(a)

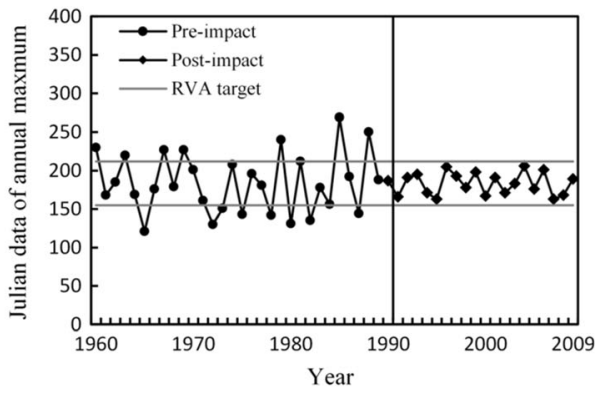

(b)

Fig. 3 RVA result of monthly March flow a and Julian data of annual maximum $\mathbf{b}$ at Sanshui station

\subsection{Periodicity Analysis}

The periodicities of the 32 IHA parameters were examined using Morlet wavelet analysis. Figure 4 shows the real part of Morlet wavelet transform coefficient for monthly October flow series at Sanshui station and monthly September flow at Makou station. In Fig. 4, the positive and negative variations represent wet and dry periods, respectively. As shown in Fig. 4, at Sanshui station, quasi-periodic variations can be seen on the time scales of 3-6 years, 812 years, and $13-16$ years in the pre-impact period and $2-4$ years, 6-8 years, and 9-13 years in the post-impact period. Moreover, at the Makou station, quasi-periodic times for monthly

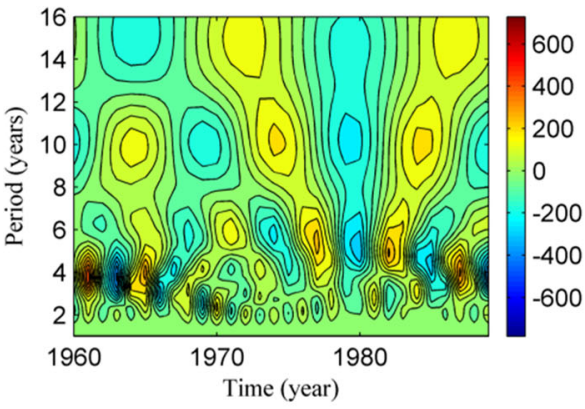

(a)

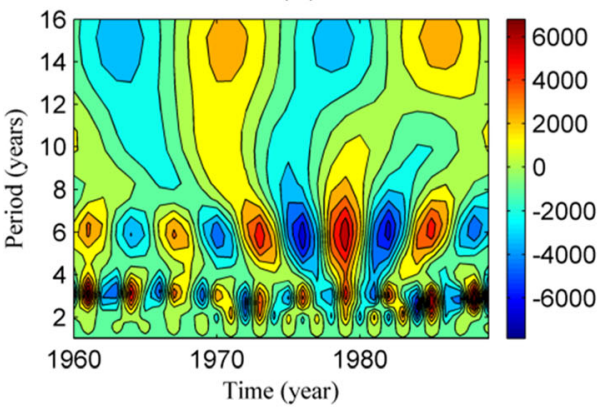

(c)

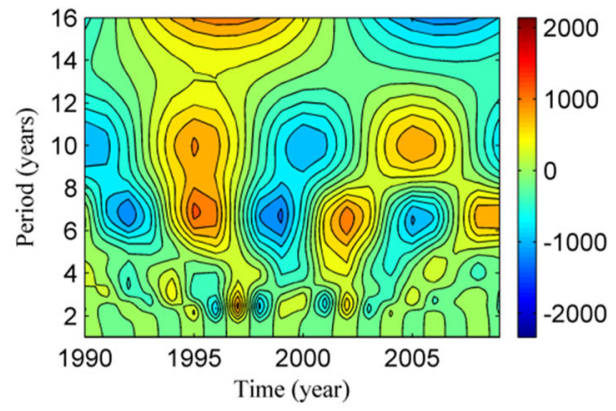

(b)

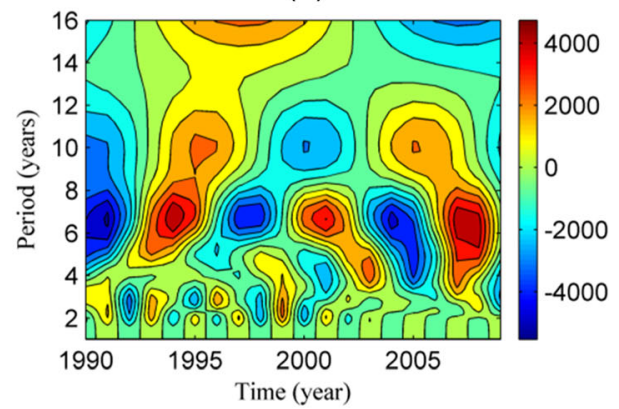

(d)

Fig. 4 The real part of Morlet wavelet transform coefficient of monthly October flow at Sanshui station a-b and monthly September flow at Makou station c-d 
September flow were $2-4$ years, 5-8 years, and 13-16 years in the pre-impact period and 58 years and 9-12 years in the post-impact period.

In order to determine the exact periodic time, the wavelet power spectrum was calculated, as shown in Fig. 5. Further, the peaks in the spectrum were examined using white- or red-noise spectrum with significant value of $95 \%$. As shown in Fig. 5a, three peaks exist in the wavelet power spectrum, with only one peak having power above the $95 \%$ line in the pre-impact period and the corresponding periodic time was 4.0 years. In the post-impact period, out of the original 3 peaks, 2 peaks are significant (Fig. 5b), and the average periodic times of peak value of these 2 power spectra are 2.5 years and 6.7 years, respectively. It should be noted that the maximum peak value corresponds to the time scale of 6.7 years, thus indicating that the 6.7year periodic time can be considered to be the first main periodic time. Further, 2.5 years was considered to be the second significant periodic time. Similarly, the main periodic times of monthly September flow at Makou station were 3.0 years and 6.0 years in the pre-impact period (Fig. 5c), and 6.7 years in the post-impact period (Fig. 5d).

The periodic times are significantly affected in the flow regime; however, these variations are not involved in the traditional RVA. In order to reveal the variability of periodicity, index for the alteration of periodicity (IP) was also calculated, and the results are shown in Table 1. As can be seen, despite the high degree of alteration at Sanshui station, 13 parameters exhibit
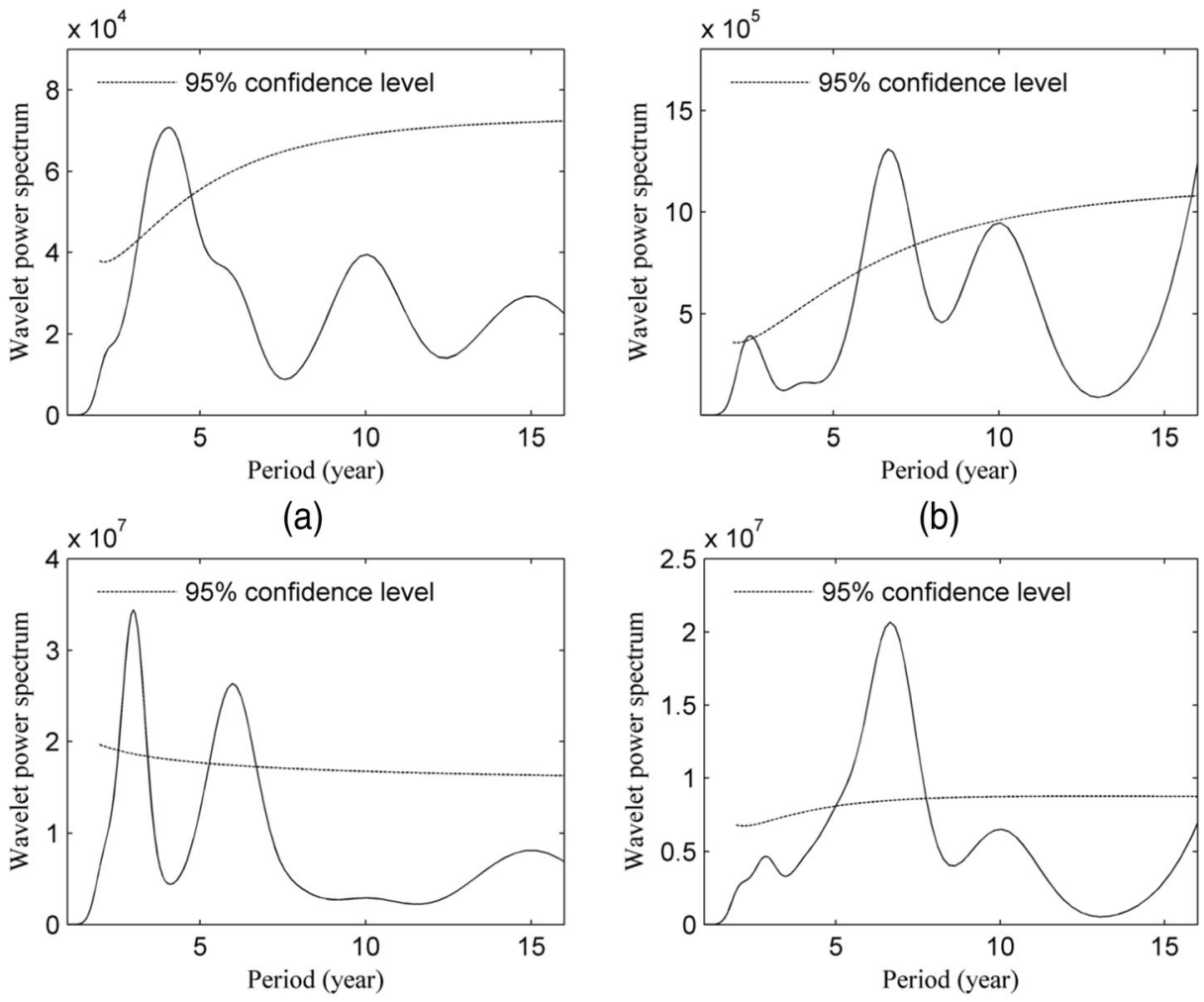

(c)

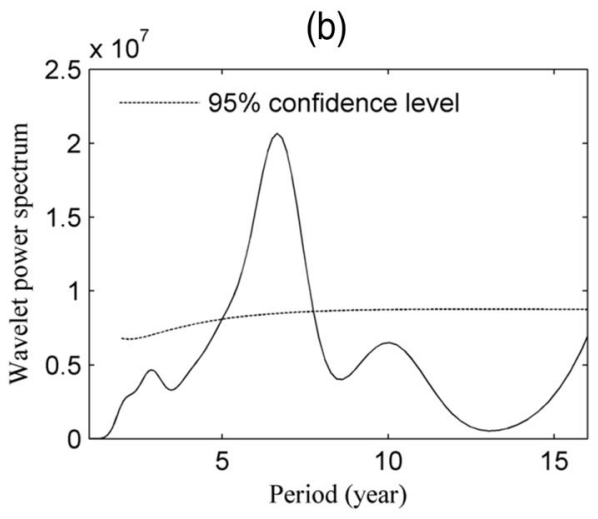

(d)

Fig. 5 The global wavelet power spectrum of monthly October flow in pre-impact a and post-impact $\mathbf{b}$ and monthly September flow in pre-impact $\mathbf{c}$ and post-impact $\mathbf{d}$ (The solid line is the wavelet power spectrum, the dashed line is the $95 \%$ confidence spectrum) 
higher IP values when compared with $\mathrm{D}_{\mathrm{R}}$ values, and for the Makou station, that number even got 28. These results show that the traditional RVA undervalued hydrologic alteration because the periodic component in the series was neglected.

\subsection{Trend Analysis}

The trend of each IHA parameter in the pre- and post-impact periods was analyzed using Mann-Kendall trend analysis, and the IT was calculated to assess hydrologic alteration considering the variability of trend. Table 1 shows that at the Sanshui station, 15 parameters exhibit a contrary trend, and 21 parameters have higher IT values than $\mathrm{D}_{R}$ values. The mean trend alteration of 1.04 is significantly greater than the average $D_{R}$ value of 0.62 . At the Makou station, the hydrologic alteration calculated using the traditional RVA, which considers only frequency alteration, was merely 0.26 , which belongs to the category of low alteration according to Richter's criteria (Richter et al. 1996). Whereas, the mean trend alteration values of 0.68 with 10 parameters exhibited the opposite trend and 27 parameters have higher IT values when compared with $\mathrm{D}_{\mathrm{R}}$ values. Especially, some IHAs exhibit a contrary trend (Fig. 6), e.g., the 3-day maximum flow parameters (Fig. 6a). Similar variation of trend can be seen in the case of Makou station also, such as the monthly December flow (Fig. 6d) and 7day maximum flow (Fig. 6e). The results indicated that the traditional RVA underestimated the hydrologic alteration on flow regime. Therefore, to obtain more accurate results, the trend component must be taken into account.

\subsection{Symmetry Analysis}

As mentioned earlier, the time periods beyond the target boundaries are neglected in the traditional RVA. Therefore, symmetry analysis method was proposed to overcome this limitation. The boundaries of asymmetry were set to be the same as those in the traditional RVA; therefore, IS must be 0 in the pre-impact period, thus indicating that the hydrologic series is unbiased. The symmetry of hydrologic parameters in the post-impact period can then be reflected by the IS value.

The IS values of IHAs at Sanshui and Makou stations were calculated using Eq. (13), and the results are listed in Table 1. In general, 28 out of 32 parameters clearly exhibit an upward bias; 18 out of 32 parameters are $100 \%$ altered, and only 2 parameters exhibit no bias in symmetry. Overall 20 parameters have higher IS values when compared with $D_{R}$ values, and the mean IS value is 0.83 , which is significantly higher than the average $D_{R}$ value. Moreover, the results for symmetry analysis at Makou station also show that the $D_{R}$ value is not sufficient to describe hydrologic alteration for 19 parameters, especially for the monthly river flow and multiday minimum flow values, which have higher IS values than $D_{R}$ values. Figure 7 shows the symmetry analysis results for some IHAs at Sanshui $(\mathrm{a}-\mathrm{c})$ and Makou $(\mathrm{d}-\mathrm{f})$ stations. The value and frequency of monthly June flow at Sanshui station (Fig. 7a) typically increased in the post-impact period, and no flow data can be seen below the pre-determined lower target. If we only consider the frequency within the target range, the alteration calculated using the traditional RVA is 0 ; however, the symmetry analysis results show that the flow regime has been significantly altered with an IS value of $100 \%$. Moreover, the monthly May flow (Fig. 7d) at Makou station have reduced since 1990, and the hydrologic alteration of that parameter was underestimated by the traditional RVA method. These results indicate that the traditional RVA cannot comprehensively evaluate the hydrologic alteration on flow regime. 


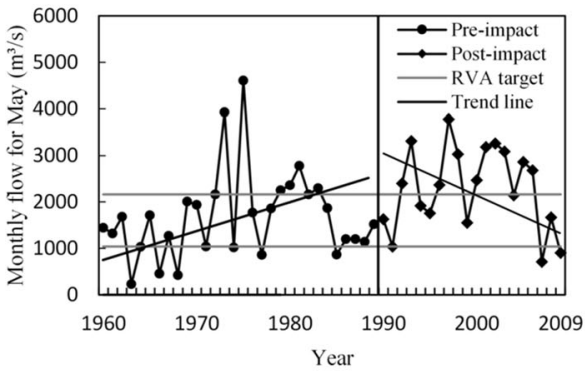

(a)

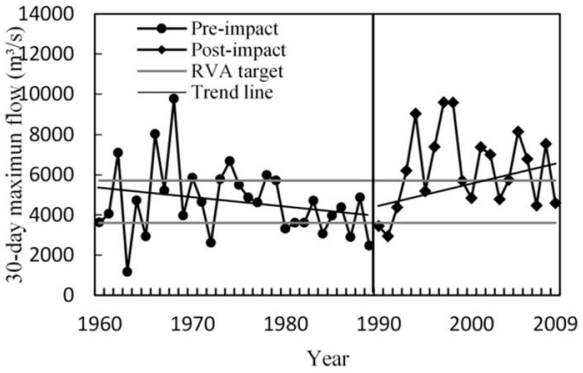

(c)

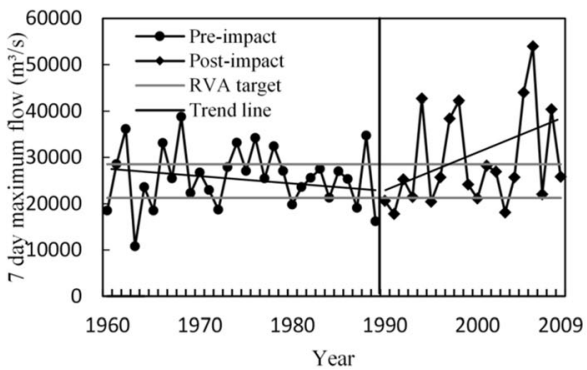

(e)

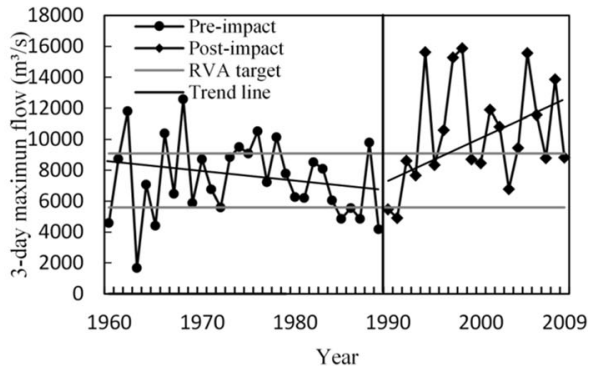

(b)

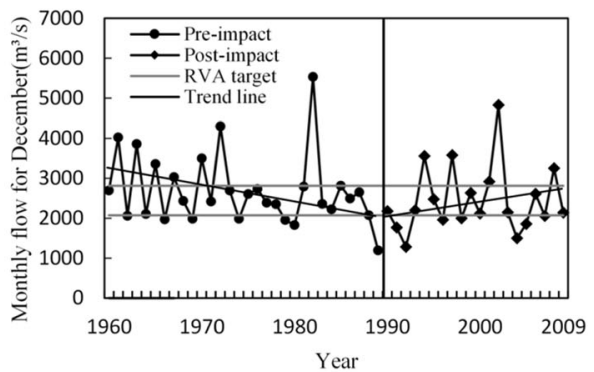

(d)

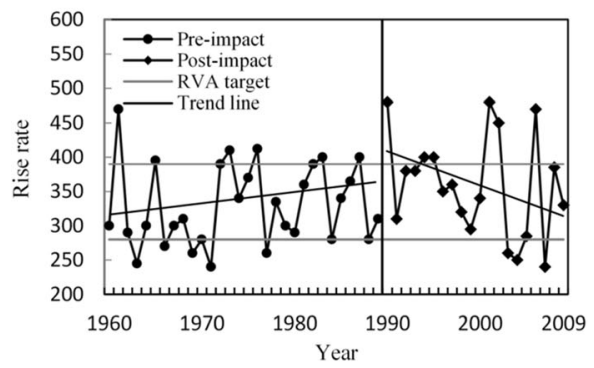

(f)

Fig. 6 Trend analysis of some IHAs at Sanshui station a-c and Makou station d-f

\section{Discussion}

A comparison between the traditional and improved RVA shows that the traditional RVA cannot accurately reflect the full picture of alteration of each IHA. Several studies have conducted to improve the performance of RVA, such as the fuzzy approach proposed by Suen and Eheart (2006) and Bizzi et al. (2012), the histogram-matching approach proposed by Shiau and $\mathrm{Wu}$ (2008), and an entropy-based multi-criteria decision method proposed by Kim and Singh (2014). However, all these methods fail to consider the order of each IHA, which is also an important factor influencing the aquatic health of a river basin.

According to the above analysis, the periodicity, trend, and symmetry of hydrologic indices have been altered in the PRD. The difference in the order and symmetry of these parameters can be attributed to the integrated effects of climate change and human activities. These two factors exert varying influences in different time intervals and on different time scales. Generally, the periodic 


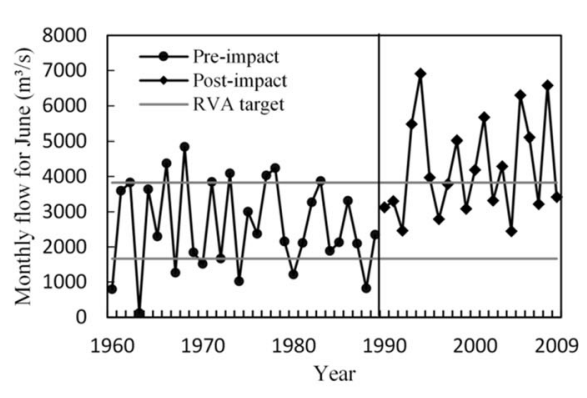

(a)

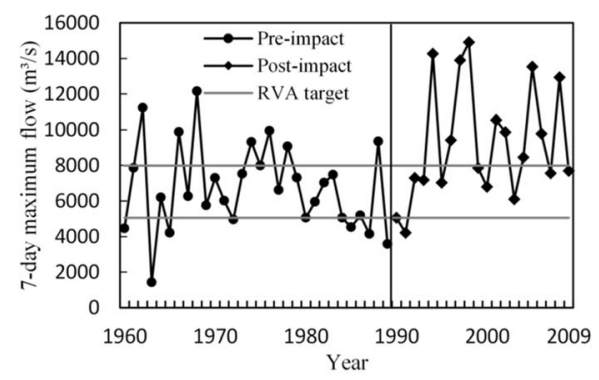

(c)

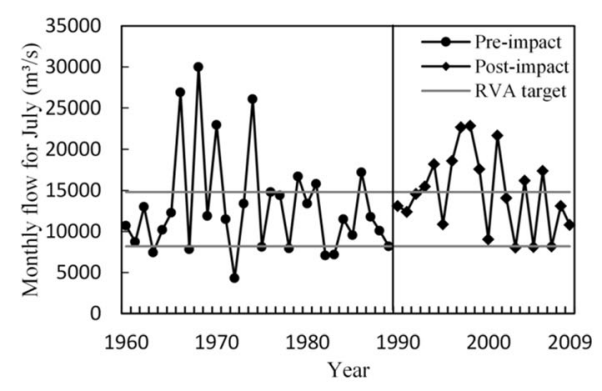

(e)

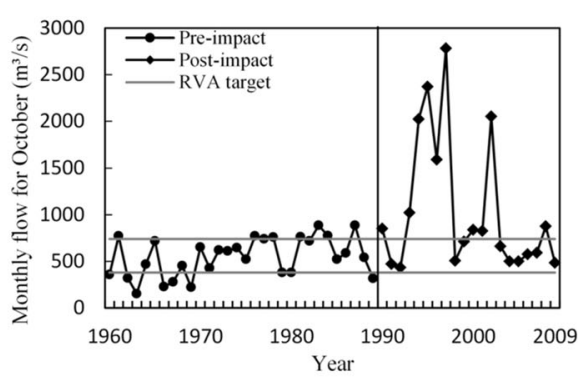

(b)

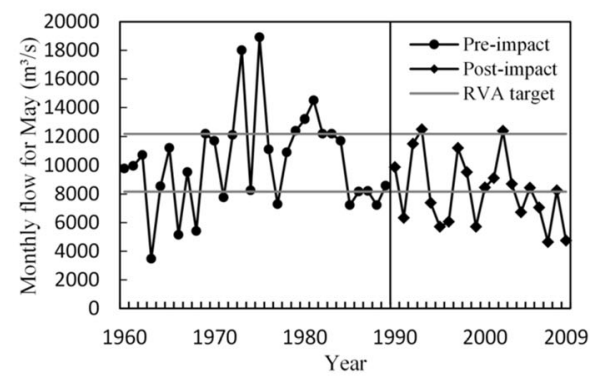

(d)

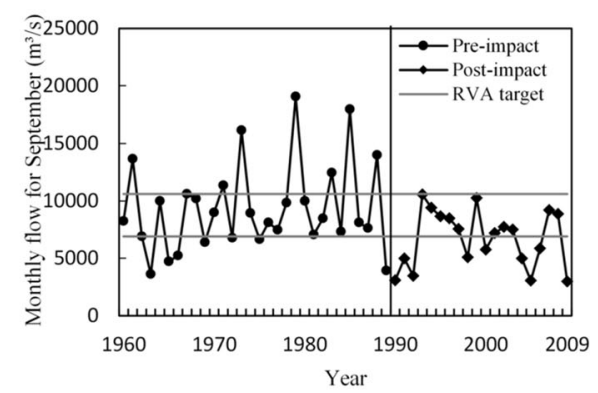

(f)

Fig. 7 Symmetry analysis result of some parameters at Sanshui station a-c and Makou station d-f

changes in annual hydrologic series are primarily controlled by climate. Zhang et al. (2009) found that the precipitation of the Pearl River basin has been decreasing since the late 1990s. Further, the dominant variabilities of precipitation in the Pearl River basin were essentially influenced by the Indian Ocean Dipole (IOD) and El Niño-Southern Oscillation (ENSO) (Niu 2013).

On the other hand, the symmetry of hydrologic indices is primarily affected by human activities, while the variation in trend can be attributed to the integrated effect of climate change and human activities in the PRD (Zhang et al. 2009; 2011). As the fastest developing region in China, the hydrology and morphology of the PRD have been predominantly impacted by human activities over the last 20 years. Some researchers (e.g., Chen and Chen 2002; Luo et al. 2007; Liu et al. 2014) found that large-scale dredging and excavation of river sand significantly affect the morphology of river channels and hydrologic deformation. On the basis of field surveys of excavating activities and river hypsography, Luo et al. (2007) reported that more than $8.7 \times 10^{8} \mathrm{~m}^{3}$ of sand was excavated between 1986 and 2003, resulting in average down- 
cutting depths of $0.59-1.73 \mathrm{~m}$ and $0.34-4.43 \mathrm{~m}$ in the main channels of the West River and North River, respectively. Variations in the geometrical shapes of the river channels altered streamflow ratio between the North River and West River, which was considered to be another major factor causing hydrologic alterations in the PRD (Chen and Chen 2002; Luo et al. 2007; Zhang et al. 2011). Therefore, when compared with the traditional RVA, the improved RVA gives a more comprehensive representation of hydrologic alteration due to nature and human activities. Hence, the improved RVA is useful for better protecting ecosystems by evaluating and managing water resources so as to ensure sustainable socioeconomic development of the PRD.

\section{Conclusion}

Hydrologic alteration is an important topic in hydrology. In this study, considering the order and symmetry of IHA, three indices (IT, IP, and IS) were used to improve the applicability of traditional RVA for comprehensively assessing hydrologic alteration. The two main gauging stations in the PRD, the Makou and Sanshui stations, were selected for this study. The major findings are as follows:

(1) Periodicity analysis can be used to identify the precise periodic time of each IHA, and significant variations were found at both two stations. However, the traditional RVA neglects the variation in periodicity, thus leading to underestimated hydrologic alteration. With low degree of hydrologic alteration assessed by the traditional RVA, the monthly flows for August and October and 90-day maximum flow at Sanshui station and the majority of parameters at Makou station had larger IP values. Therefore, as one of the most important components of the time series, periodicity alteration must be also taken into account to accurately estimate hydrologic alteration.

(2) Trend analysis results show that the alteration in the trend component is not reflected in the traditional RVA. Obvious variations were found in the trend of IHAs at Sanshui station, the trend can be found significant in the pre-impact period, while that were nonsignificant in the post-impact period. Further, the monthly river flows in the flood season and multiday maximum flow exhibited different trends from the pre-impact period. Moreover, although parameters such as monthly December flow, 7-day maximum flow, and rise rate at Makou station were also significantly altered, while the result of the traditional RVA was a low value. Therefore, the index for the alteration of trend must be considered to obtain more accurate results.

(3) The results of symmetry analysis showed that the symmetry of most of the IHAs at Sanshui station increased significantly, and the results corresponding to Makou station were more complicated. The $D_{R}$ values were somewhat low in the monthly flows for June and October and 7-day maximum flow at Sanshui station and monthly flows for May, July, and September at Makou station, while their degrees of symmetry were extremely high. By including the IS, the improved RVA can give a more comprehensive hydrologic alteration assessment.

Flow regime alteration is one of the primary drivers for a number of fundamental ecological processes in river ecosystems. The results of this study provide some useful information for better water resource management to ensure ecosystem sustainability and adequate water supply in the region. 
Acknowledgments The research is financially supported by the National Natural Science Foundation of China (Grant Nos.: 51379223 and 51579180).

Open Access This article is distributed under the terms of the Creative Commons Attribution 4.0 International License (http://creativecommons.org/licenses/by/4.0/), which permits unrestricted use, distribution, and reproduction in any medium, provided you give appropriate credit to the original author(s) and the source, provide a link to the Creative Commons license, and indicate if changes were made.

\section{References}

Bizzi S, Pianosi F, Soncini-Sessa R (2012) Valuing hydrological alteration in multi-objective water resources management. J Hydrol 472:277-286

Bott TL, Montgomery DS, Newbold JD, Arscott DB, Dow CL, Aufdenkampe AK, Jackson JK, Kaplan LA (2006) Ecosystem metabolism in stream of the Catskill Mountains (Delaware and Hudson River watersheds) and lower Hudson Valley. J N Am Benthol Soc 25:1018-1044

Brockwell PJ, Davis RA (2002) Introduction to time series and forecasting, 2nd edn. Springer-Verlag: Berlin; 469

Chen XH, Chen YD (2002) Hydrological change and its causes in the river network of the Pearl River Delta. Acta Geograph Sin 57(4):430-436 (in Chinese)

Chen H, Guo SL, CY X, Singh VP (2007) Historical temporal trends of hydro-climatic variables and runoff response to climate variability and their relevance in water resource management in the Hanjiang basin. $\mathrm{J}$ Hydrol 344:171-184

Chen YD, Zhang Q, Chen XH, Wang P (2012) Multiscale variability of streamflow changes in the Pearl River basin, China. Stoch Env Res Risk A 26:235-246

Dai SB, Yang SL, Cai AM (2008) Impacts of dams on the sediment flux of the Pearl River, southern China. Catena 76:36-43

Ericson JP, Vorosmarty CJ, Dingman SL, Ward LG, Meybeck M (2006) Effective Sea-level rise and deltas: causes of change and human dimension implications. Glob Planet Chang 50:63-82

Farge M (1992) Wavelet transforms and their applications to turbulence. Annu Rev Fluid Mech 24:395-457

Gao B, DW Y, TTG Z, Huang Y (2012) Changes in the eco-flow metrics of the upper Yangtze River from 1961 to 2008. J Hydrol 448-449:30-38

Gerstengarbe F, Werner P (1999) Estimation of the beginning and end of recurrent events within a climate regime. Clim Res 11:97-107

He Y, Lin K, Chen X, Ye C, Cheng L (2015) Classification-based spatiotemporal variations of pan evaporation across the Guangdong Province, South China. Water Resour Manag 29:901-912

Hu WW, Wang GX, Deng W, Li SN (2008) The influence of dams on ecohydrological conditions in the Huaihe River basin, China. Ecol Eng 33(3-4):233-241

Karabork MC (2007) Trends in drought patterns of Turkey. J Environ Eng 6:45-52

Kim Z, Singh VP (2014) Assessment of environmental flow requirements by entropy-based multi-criteria decision. Water Resour Manag 28:459-474

Laize CL, Acreman MC, Schneider C, Dunbar MJ, Houghton-carr HA, Florke M, Hannah DM (2014) Projected flow alteration and ecological risk for Pan-European Rivers. River Res Appl 30:299-314

Li X, Guo S, Liu P, Chen G (2010) Dynamic control of flood limited water level for reservoir operation by considering inflow uncertainty. J Hydrol 391:126-134

Lin K, Lian Y, Chen X, Lu F (2014) Changes in runoffs and eco-flows in the Dongjiang River of the Pearl River basin, China. Front. Earth Sci 8(4):547-557

Liu P, Guo S, Xiong L, Li W, Zhang H (2006) Deriving reservoir refill operating rules by using the proposed DPNS model. Water Resour Manag 20:337-357

Liu F, Yuan L, Yang Q, Ou S, Xie L, Cui X (2014) Hydrological responses to the combined influence of diverse human activities in the Pearl River Delta, China. Catena 113:41-55

Liu P, Li L, Guo S, Xiong L, Zhang W, Zhang J, Xu C (2015) Optimal design of seasonal flood limited water levels and its application for the three gorges reservoir. J Hydrol 527:1045-1053

Luo XL, Zeng EY, Ji RY, Wang CP (2007) Effects of in-channel sand excavation on the hydrology of the Pearl River Delta, China. J Hydrol 343:230-239

Mittal N, Bhave AG, Mishra A, Singh R (2016) Impact of human intervention and climate change on natural flow regime. Water Resour Manag 30:685-699

Niu (2013) Precipitation in the Pearl River basin, South China: scaling, regional patterns, and influence of largescale climate anomalies. Stoch Env Res Risk A 27:1253-1268 
Ouyang W, Hao H, Song K, Zhang X (2011) Cascade dam-induced hydrological disturbance and environmental impact in the upper stream of the Yellow River. Water Resour Manag 25:913-927

Poff NL, Zimmerman JKH (2010) Ecological responses to altered flow regimes: a literature review to inform the science and management of environmental flows. Freshw Biol 55:194-205

Richter BD, Baumgartner JV, Powell J, Braun DP (1996) A method for assessing hydrologic alteration within ecosystems. Conserv Biol 10(4):1163-1174

Richter BD, Warner AT, Meyer JL, Lutz K (2006) A collaborative and adaptive process for developing environmental flow recommendations. River Res Appl 22:297-318

Shiau JT, Wu FC (2008) A histogram matching approach for assessment of flow regime alteration: application to environmental flow optimization. River Res Appl 24:914-928

Suen JP, Eheart JW (2006) Reservoir management to balance ecosystem and human needs: incorporating the paradigm of the ecological flow regime. Water Resour Res 42:W03417. doi:10.1029/2005WR004314

Sun T, Feng ML (2013) Multistage analysis of hydrologic alterations in the Yellow River China. River Res Appl 29:991-1003

Torrence C, Compo GP (1998) A practical guide to wavelet analysis. Bull Am Meteorol Soc 79:61-78

Yang P, Yin XA, Yang ZF, Tang J (2014) A revised range of variability approach considering the periodicity of hydrological indicators. Hydrol Process 28:6222-6235

Yang ZF, Yan Y, Liu Q (2012) Assessment of the flow regime alterations in the lower Yellow River, China. Ecol Inform 10:56-64

Zhang Q, CY X, Chen YD (2009) Abrupt behaviors of the streamflow of the Pearl River basin and implications for hydrological alterations across the Pearl River Delta, China. J Hydrol 377:274-283

Zhang Q, Chen YD, Jiang T, Chen X, Liu Z (2011) Human-induced regulations of river channels and implications for hydrological alterations in the Pearl River Delta, China. Stoch Environ Res Risk Assess Stochastic 25:1001-1011 